\title{
Effect of Adequate Thyroid Hormone Replacement on the Hypothalamo-Pituitary- Gonadal Axis in Premenopausal Women with Primary Hypothyroidism
}

\author{
Bharath Bachimanchi Suresh Vaikkakara Alok Sachan Ganji Praveen Kumar \\ Ashok Venkatanarasu Palaparti Sai Krishna Chaitanya Bekkem Sreedivya \\ Ravi Poojari
}

Department of Endocrinology \& Metabolism, Sri Venkateswara Institute of Medical Sciences, Tirupati, India

\section{Keywords \\ Thyroid hormones · Hypothalamo-pituitary-gonadal axis · \\ Premenopausal women · Primary hypothyroidism}

\begin{abstract}
Background: While the effects of thyroxine $\left(T_{4}\right)$ replacement on improving gonadal function in hypothyroid men has been well documented, the same has not been adequately studied in hypothyroid premenopausal women. Methodology: Premenopausal women with overt hypothyroidism (thyroid-stimulating hormone $[\mathrm{TSH}]>15 \mathrm{IU} / \mathrm{L}$ ) were tested in the early follicular phase of their natural menstrual cycles or after a progesterone challenge for gonadotropins, estradiol $\left(E_{2}\right)$, and prolactin (PRL). They were then treated adequately with $\mathrm{T}_{4}$ replacement and retested under similar circumstances for the same parameters $\geq 2$ months after the restoration of euthyroidism. Results: Forty premenopausal hypothyroid women were evaluated at baseline and $\geq 2$ months after adequate $\mathrm{T}_{4}$ replacement. At baseline, there was an inverse correlation of the gonadotropins (luteinizing hormone $[\mathrm{LH}]$ and follicle-stimulating hormone $[\mathrm{FSH}]$ ) and $\mathrm{TSH}$, prolactin (PRL)
\end{abstract}

and free $T_{4}\left(\mathrm{fT}_{4}\right)$, and $\mathrm{E}_{2}$ and PRL. After normalization of the thyroid function, there was a significant fall in PRL $(p<0.001)$ accompanied by a rise in serum $\mathrm{E}_{2}(p<0.001)$. There were no changes in the levels of the gonadotropins $\mathrm{LH}$ and $\mathrm{FSH}$. The proportion of patients with hyperprolactinemia fell 5-fold, from $5 / 40$ to $1 / 40$. While there were 5 patients with low estrogen prior to treatment, there were none with hypoestrogenemia after treatment. Conclusion: Hypothyroidism is associated with a reversible partial suppression of the hypothalamo-pituitary-gonadal axis in premenopausal women, demonstrated by lower $E_{2}$ along with a mild elevation of PRL. Treatment of hypothyroidism improves the level of estrogen and lowers the level of PRL.

(c) 2019 European Thyroid Association Published by S. Karger AG, Basel

\section{Introduction}

Hypothyroidism is widely prevalent all over the world including India. The incidence of overt hypothyroidism has been estimated to be 4.1 cases per 1,000 women per year and 0.6 cases per 1,000 men per year [1].

\section{KARGER}

E-Mail karger@karger.com www.karger.com/etj
Prof. Suresh Vaikkakara

Department of Endocrinology and Metabolism Sri Venkateswara Institute of Medical Sciences

Tirupati 517501, Andhra Pradesh (India) 
Table 1. Details of immunoassay kits used for the measurement of various hormones

\begin{tabular}{|c|c|c|c|c|c|}
\hline Hormone & Kit name & Method & $\begin{array}{l}\text { Measurement } \\
\text { range }\end{array}$ & $\begin{array}{l}\text { Range of intra-assay } \\
\text { CV at different mean } \\
\text { hormone levels, } \%\end{array}$ & Normal range \\
\hline TSH, mIU/L & $\begin{array}{l}\text { Beckman } \\
\text { Coulter } \\
\text { Access }\end{array}$ & CLIA & $0.01-100$ & $2.49-5.83$ & $0.5-5$ \\
\hline Total $\mathrm{T}_{4}, \mathrm{nmol} / \mathrm{L}$ & $\begin{array}{l}\text { Beckman } \\
\text { Coulter } \\
\text { Access }\end{array}$ & CLIA & $6.44-3,861$ & $3.16-5.08$ & $77.23-157$ \\
\hline Free $\mathrm{T}_{4}, \mathrm{pmol} / \mathrm{L}$ & $\begin{array}{l}\text { Beckman } \\
\text { Coulter } \\
\text { Access }\end{array}$ & CLIA & $3.25-77.6$ & $1.82-4.40$ & $7.85-14.42$ \\
\hline FSH, IU/L & $\begin{array}{l}\text { Beckman } \\
\text { Coulter } \\
\text { Access }\end{array}$ & CLIA & $0.2-200$ & $3.1-4.3$ & $3.85-8.75$ \\
\hline LH, IU/L & $\begin{array}{l}\text { Beckman } \\
\text { Coulter } \\
\text { Access }\end{array}$ & CLIA & $0.2-250$ & $3.6-5.4$ & $2.12-10.89$ \\
\hline $\mathrm{PRL}, \mathrm{pmol} / \mathrm{L}$ & $\begin{array}{l}\text { Beckman } \\
\text { Coulter } \\
\text { Access }\end{array}$ & CLIA & $10.87-8,695.6$ & $1.42-1.61$ & $145.3-1,161.72$ \\
\hline $\mathrm{E}_{2}, \mathrm{pmol} / \mathrm{L}$ & $\begin{array}{l}\text { Beckman } \\
\text { Coulter } \\
\text { Access }\end{array}$ & CLIA & $73.42-176.20$ & $2.0-5.0$ & $73.42-550$ \\
\hline
\end{tabular}

TSH, thyroid-stimulating hormone; $\mathrm{LH}$, luteinizing hormone; FSH, follicle-stimulating hormone; $\mathrm{T}_{4}$, thyroxine; PRL, prolactin; CV, coefficient of variation; CLIA, chemiluminescence immunoassay.

Thyroxine $\left(T_{4}\right)$ has a permissive effect on reproduction. Hypothyroidism has been shown to have a suppressive effect on the function of the hypothalamo-pituitary-gonadal (HPG) axis in both men [2-7] and women [8]. However, while there are a number of studies on men, prospectively documenting the beneficial effect of $\mathrm{T}_{4}$ replacement on male gonadal function, there is a dearth of such studies on women. We planned to document changes from baseline in the levels of estradiol $\left(\mathrm{E}_{2}\right)$, follicle-stimulating hormone (FSH), luteinizing hormone (LH), and prolactin (PRL) $\geq 2$ months after the normalization of thyroid-stimulating hormone (TSH) in hypothyroid women.

\section{Materials and Methods}

This study was a prospective, longitudinal, before/after, interventional study. Premenopausal women aged $>18$ years attending Endocrine Services at the Sri Venkateswara Institute of Medical Sciences with newly diagnosed or inadequately treated primary hypothyroidism (TSH $>15 \mathrm{mIU} / \mathrm{L}$ ) were recruited for the study after giving their informed consent. Women with a known disease of the pituitary gland, and those who were pregnant, on medication, or suffering from any other diseases likely to affect the HPG axis or serum PRL were excluded.

Patients were counseled to come after an overnight fast for blood sample collection on days $2-5$ of the next menstrual cycle. If the patient had irregular periods and the last menstrual period had occurred $>35$ days prior to the date of examination, then, after confirming they were not pregnant, the women were advised to take $10 \mathrm{mg}$ medroxyprogesterone acetate at bedtime for 7 days and to stop it thereafter. When a progesterone-withdrawal bleed occurred, patients were advised to present themselves on the 2nd5th day after the onset of menstrual bleeding to provide a blood sample in the fasting state. Alternatively, women with prolonged menstrual cycles who preferred to wait for their delayed but natural periods were permitted to do so, and they provided the blood sample on the 2nd-5th day of their next menstrual period. Height and weight were recorded. The blood sample was collected in the fasting state under resting conditions as 3 equal aliquots $20 \mathrm{~min}$ apart, pooled, and then stored at $-40^{\circ} \mathrm{C}$ pending analysis. The details of the hormones that were assessed and the methods used are given in Table 1 . The patients were then started on $\mathrm{T}_{4}$ replacement 
Fig. 1. Flow chart depicting the manner of patient recruitment.

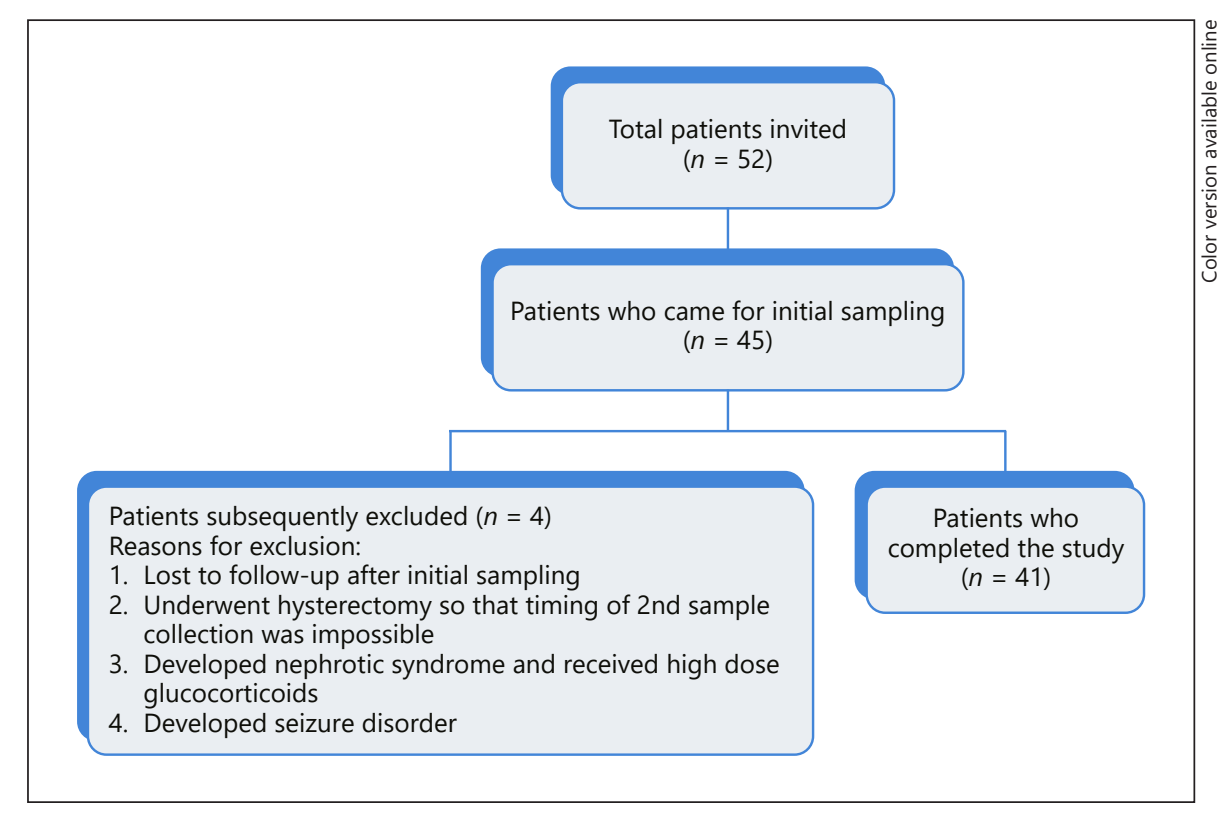

in doses titrated to achieve a normal TSH of $0.5-5 \mathrm{mIU} / \mathrm{L}$. Two months or more after achieving euthyroid status (reconfirmed by TSH testing), repeat blood samples were collected from the patients, again on days 2-5 of a natural menstrual cycle or after a progesterone-withdrawal bleed as before. Parameters tested again were $\mathrm{TSH}$, free $\mathrm{T}_{4}\left(\mathrm{fT}_{4}\right)$, total $\mathrm{T}_{4}, \mathrm{E}_{2}, \mathrm{FSH}, \mathrm{LH}$, and PRL.

\section{Data Analysis}

Continuous variables (BMI, $\mathrm{LH}, \mathrm{FSH}, \mathrm{E}_{2}$, PRL, etc.) were expressed as median (interquartile range [IQR]). Comparisons between baseline and posttreatment values for each hormone were performed by the paired $t$ test or the Wilcoxon signed-rank test for normally or non-normally distributed data, respectively. Comparison of proportions between baseline and post-treatment were done by the McNemar $\chi^{2}$ test for paired data. $p<0.05$ was considered significant for all the above tests. For the purpose of statistical tests including correlations and tests of significance, values of TSH $>100 \mathrm{mIU} / \mathrm{L}$ were taken as $100 \mathrm{mIU} / \mathrm{L}$.

\section{Results}

A total of 52 consecutive women fulfilling all inclusion criteria were invited to participate, but only 45 patients consented to enter the study. Four more patients were excluded subsequent to their initial recruitment and sample collection, as they developed new confounding medical disorders that might have had an effect on their HPG axis and/or PRL level, or on determining the time of sampling. The details about the recruitment process and the reasons for the exclusion of the above 4 patients are given in Figure 1.
Of the remaining 41 patients who completed the study, one patient aged 31 years had to be excluded from the analysis as an "outlier" with respect to her post-treatment gonadotropins. She had an initial $\mathrm{LH}$ of $0.97 \mathrm{IU} / \mathrm{L}$ and FSH of $3.53 \mathrm{IU} / \mathrm{L}$, along with $\mathrm{E}_{2}$ of $51.39 \mathrm{pmol} / \mathrm{L}$ with hypothyroidism (TSH $>100 \mathrm{miU} / \mathrm{L}$ ) and irregular periods. After restoring her to an euthyroid state (TSH $3.03 \mathrm{mIU} / \mathrm{L}$ ), she had an inexplicable increase in both her gonadotropins (LH 25.56 IU/L and FSH 62.62 IU/L) to near-castrate levels, and her $\mathrm{E}_{2}$ rose to $176.21 \mathrm{pg} / \mathrm{L}$. She did not follow up later, but, on phone contact, reported herself to be feeling well and having regular menstrual cycles. Her PRL, which was $2,443 \mathrm{pmol} / \mathrm{L}$ before treatment, fell to 414 $\mathrm{pmol} / \mathrm{L}$ after correcting the hypothyroidism.

Of the remaining 40 women, median age was 31 (IQR 23-34) years. Menstrual cycles were regular with normal duration (i.e., $21-35$ days) in 26 patients (65\%). All 40 women had overt hypothyroidism: median TSH $>100$ (IQR 48->100) mIU/L and median $\mathrm{fT}_{4} 4.8$ (IQR 3-7.4) $\mathrm{pmol} / \mathrm{L}$. Patients were sampled either after a spontaneous menstrual cycle $(n=28 ; 26$ had regular menstrual cycles of normal length and 2 had prolonged menstrual cycles but chose to wait for their next natural period), or after a progesterone-withdrawal bleed was observed $(n=12)$. All the women were parous except for 4 , who had yet not married.

Five of the 40 patients had hyperprolactinemia (i.e., $\mathrm{PRL}>1,158.6 \mathrm{pmol} / \mathrm{L})$. No patient reported galactorrhea. On comparing patients with hyperprolactinemia with the 
Table 2. Comparison of hormones in patients with low $(<73.42 \mathrm{pmol} / \mathrm{L})$ and normal $\mathrm{E}_{2}$ levels in 40 hypothyroid women before treatment

\begin{tabular}{lcll}
\hline & $\begin{array}{l}\text { Patients with } \mathrm{E}_{2} \\
<73.42 \mathrm{pmol} / \mathrm{L} \\
(n=5)\end{array}$ & $\begin{array}{l}\text { Patients with } \\
\text { normal } \mathrm{E}_{2} \\
(n=35)\end{array}$ & $p$ value \\
\hline Free $\mathrm{T}_{4}, \mathrm{pmol} / \mathrm{L}$ & $3.9(1.5-4.3)$ & $5.5(3.3-7.6)$ & 0.069 \\
$\mathrm{FSH}, \mathrm{IU} / \mathrm{L}$ & $3.5(2.1-3.5)$ & $7.8(6.5-9.4)$ & 0.039 \\
$\mathrm{LH}, \mathrm{IU} / \mathrm{L}$ & $2.3(0.9-3.3)$ & $5.0(3.1-7.7)$ & 0.009 \\
$\mathrm{PRL}, \mathrm{pmol} / \mathrm{L}$ & $867.5(830-2,208)$ & $569(421.7-773.9)$ & 0.003 \\
\hline
\end{tabular}

$p<0.05$ was considered significant. $\mathrm{E}_{2}$, estradiol; $\mathrm{LH}$, luteinizing hormone; FSH, follicle-stimulating hormone, $\mathrm{T}_{4}$, thyroxine; $\mathrm{PRL}$, prolactin.
Table 3. Correlations between different pairs of hormones in 40 hypothyroid women prior to and after treatment with $\mathrm{T}_{4}$

\begin{tabular}{|c|c|c|c|c|c|}
\hline \multirow[t]{2}{*}{ Variable 1} & \multirow[t]{2}{*}{ Variable 2} & \multicolumn{2}{|c|}{ Before treatment } & \multicolumn{2}{|c|}{ After treatment } \\
\hline & & $r$ value & $p$ value & $r$ value & $p$ value \\
\hline $\mathrm{TSH}$ & FSH & -0.366 & 0.02 & -0.115 & 0.479 \\
\hline $\mathrm{TSH}$ & $\mathrm{LH}$ & -0.340 & 0.032 & -0.097 & 0.550 \\
\hline TSH & PRL & 0.238 & 0.139 & -0.335 & 0.034 \\
\hline $\mathrm{TSH}$ & total $\mathrm{T}_{4}$ & -0.483 & 0.002 & -0.290 & 0.069 \\
\hline TSH & free $\mathrm{T}_{4}$ & -0.645 & $<0.001$ & -0.295 & 0.064 \\
\hline TSH & $\mathrm{E}_{2}$ & -0.215 & 0.183 & -0.043 & 0.791 \\
\hline Free $\mathrm{T}_{4}$ & FSH & 0.138 & 0.397 & 0.219 & 0.174 \\
\hline Free $\mathrm{T}_{4}$ & LH & 0.244 & 0.13 & 0.139 & 0.391 \\
\hline Free $\mathrm{T}_{4}$ & PRL & -0.421 & 0.007 & 0.220 & 0.173 \\
\hline Free $\mathrm{T}_{4}$ & total $\mathrm{T}_{4}$ & 0.694 & $<0.001$ & 0.448 & 0.004 \\
\hline Free $\mathrm{T}_{4}$ & $\mathrm{E}_{2}$ & 0.264 & 0.100 & 0.066 & 0.658 \\
\hline PRL & $\mathrm{E}_{2}$ & -0.422 & 0.007 & 0.117 & 0.472 \\
\hline PRL & $\mathrm{LH}$ & -0.156 & 0.341 & 0.133 & 0.413 \\
\hline PRL & FSH & -0.065 & 0.690 & 0.005 & 0.976 \\
\hline PRL & total $\mathrm{T}_{4}$ & -0.152 & 0.350 & -0.017 & 0.916 \\
\hline $\mathrm{LH}$ & FSH & 0.503 & 0.001 & 0.036 & 0.827 \\
\hline LH & total $\mathrm{T}_{4}$ & 0.209 & 0.197 & 0.104 & 0.522 \\
\hline LH & $\mathrm{E}_{2}$ & 0.299 & 0.061 & 0.302 & 0.052 \\
\hline FSH & total $\mathrm{T}_{4}$ & 0.256 & 0.111 & -0.219 & 0.174 \\
\hline FSH & $\mathrm{E}_{2}$ & 0.201 & 0.213 & -0.174 & 0.282 \\
\hline Total $\mathrm{T}_{4}$ & $\mathrm{E}_{2}$ & 0.179 & 0.268 & 0.148 & 0.361 \\
\hline
\end{tabular}

$p<0.05$ was considered significant. TSH, thyroid-stimulating hormone; LH, luteinizing hormone; $\mathrm{FSH}$, follicle-stimulating hormone; $\mathrm{T}_{4}$, thyroxine; PRL, prolactin; $\mathrm{E}_{2}$, estradiol.

rest, there was a significantly lower level of $\mathrm{fT}_{4}$, i.e., 3.0 (IQR 1.0-4.4) pmol/L in the hyperprolactinemic women versus $5.5(3.8-7.58) \mathrm{pmol} / \mathrm{L}$ in the normoprolactinemic women ( $p=0.043$ ), and a higher level of TSH, i.e., TSH > $100 \mathrm{mIU} / \mathrm{L}$ in the hyperprolactinemic women versus 78.8 $(45.8->100) \mathrm{mIU} / \mathrm{L}$ in the normoprolactinemic women $(p=0.036)$.

HPG Axis in Women with Primary Hypothyroidism
Five of the 40 patients had low estrogen $(<73.42$ pmol/L) levels. These 5 had higher TSH (>100 vs. 78.8 $\mathrm{mIU} / \mathrm{L}$ in women with normal estrogen; $p=0.036)$. PRL was higher in the hypoestrogenic women, while both the gonadotropins (LH and FSH) were lower (Table 2).

Among the various hormones tested at baseline, significant correlations between some pairs of hormones were observed (Table 3). TSH correlated negatively with both total $\mathrm{T}_{4}$ and $\mathrm{fT}_{4}$; it also correlated negatively with both gonadotropins (LH and FSH). PRL correlated negatively with both $\mathrm{fT}_{4}$ and $\mathrm{E}_{2}$. Not unsurprisingly, $\mathrm{LH}$ and FSH correlated well with each other in a positive manner, as did $\mathrm{fT}_{4}$ and total $\mathrm{T}_{4}$. No other hormone pairs were found to correlate with each other. Age and BMI also did not correlate with any of the measured hormones in any patients (data not shown).

After treatment, while $\mathrm{fT}_{4}$ correlated strongly in a positive manner with total $\mathrm{T}_{4}$, the only other correlation noted was a negative correlation between TSH and PRL.

Table 4 gives the levels of various hormones before treatment and $\geq 2$ months after restoration to the euthyroid state in 40 women with hypothyroidism. After normalization of the thyroid function, there was a significant fall in PRL, accompanied by a rise in serum $\mathrm{E}_{2}$. There were no changes in the levels of the gonadotropins LH and FSH. The proportion of patients with hyperprolactinemia $(1,158.6 \mathrm{pmol} / \mathrm{L})$ fell 5 -fold, from 5 to $1 / 40(p=0.219)$. While there were 5 patients with low estrogen $(<73.42$ $\mathrm{pmol} / \mathrm{L}$ ) prior to treatment, there were no patients with hypoestrogenemia post-treatment.

\section{Discussion}

$\mathrm{T}_{4}$ is an important determinant of body metabolism. It plays a permissive role in maintaining normal reproductive function [9]. Overt hypothyroidism, defined as an 
Table 4. Weight and hormonal parameters before treatment and $>2$ months after adequate replacement of $\mathrm{T}_{4}$ in 40 hypothyroid women

\begin{tabular}{lccr}
\hline & At the time of initial evaluation & After adequate replacement of $\mathrm{T}_{4}$ & $p$ value \\
\hline Weight, kg & $56.5(51.12-64.1)$ & $56(50-63.3)$ & 0.111 \\
TSH, mIU/L & $>100(48->100)$ & $1.15(0.5-2)$ & $<0.001$ \\
Total T, nmol/L & $57.9(28.1-81.3)$ & $148.54(118.5-172.5)$ & $<0.001$ \\
Free $\mathrm{T}_{4}, \mathrm{pmol} / \mathrm{L}$ & $4.8(3-7.4)$ & $14.0(11.6-17.1)$ & $<0.001$ \\
$\mathrm{FSH}, \mathrm{IU} / \mathrm{L}$ & $7.7(4.7-9.3)$ & $7.4(5.3-9.2)$ & 0.788 \\
$\mathrm{LH}, \mathrm{IU} / \mathrm{L}$ & $4.7(2.8-7.5)$ & $6.2(3.9-8.7)$ & 0.132 \\
$\mathrm{PRL}, \mathrm{pmol} / \mathrm{L}$ & $613(426-821.7)$ & $391.3(256-551)$ & $<0.001$ \\
$\mathrm{E}_{2}, \mathrm{pmol} / \mathrm{L}$ & $48.50(32.2-55.8)$ & $60.00(50.2-101.8)$ & $<0.001$ \\
\hline
\end{tabular}

Values are expressed as median (IQR). $p<0.05$ was considered significant. TSH, thyroid-stimulating hormone; $\mathrm{LH}$, luteinizing hormone; $\mathrm{FSH}$, follicle-stimulating hormone; $\mathrm{T}_{4}$, thyroxine; PRL, prolactin; $\mathrm{E}_{2}$, estradiol.

elevated TSH, in combination with a subnormal $\mathrm{fT}_{4}[10]$, is a common disease affecting women of reproductive age [1]. Even though hypothyroidism is a well-documented cause of menstrual irregularities and infertility, changes in the activity of the HPG axis in women with hypothyroidism have not been adequately studied. Moreover, the response of early follicular-phase gonadotropins and estrogen in premenopausal hypothyroid women to treatment with $\mathrm{T}_{4}$ has only been reported in one study so far [8]. That particular study also included patients with subclinical primary hypothyroidism, where changes before and after treatment are likely to be minimal. Part of the problem when assessing the HPG axis is the need to standardize the timing of the assessment in relation to ovulation and the menstrual cycle, in view of the profound cyclic alterations in gonadotropins and estrogen at different stages of the menstrual cycle. Sawin et al. [11] showed that there is no effect of menstrual-phase (early follicular, periovulatory, or midluteal phase) estrogen and progesterone levels on TSH and PRL responses to thyrotropinreleasing hormone. There is therefore probably no need to standardize the timing of sample collection for these parameters (TSH and PRL).

Nevertheless, we took care to ensure that the patients were all in the early follicular phase by sampling them on the 2nd-5th day of either a natural menstrual cycle $(n=28)$ or a progesterone challenge-induced withdrawal bleed $(n=12)$. We also ensured that all our patients had overt (TSH $>15 \mathrm{mIU} / \mathrm{L}$ ) rather than subclinical hypothyroidism, so that changes in HPG axis, if any, would be more easily detected.

\section{HPG Axis and Thyroid Function in Hypothyroid Women}

The recruited patients had overt hypothyroidism at baseline: median TSH $>100$ (IQR 48->100) $\mathrm{mIU} / \mathrm{L}$ and $\mathrm{fT}_{4} 4.8(3-7.4) \mathrm{pmol} / \mathrm{L}$. However, the $\mathrm{E}_{2}$ and gonadotropin levels were within the normal range. Functionally, the patients appeared to be adequately estrogenized as they experienced either spontaneous menstrual bleeding $(n=$ $28)$ or progesterone-withdrawal bleeding $(n=12)$.

The composite picture that emerges from the correlations in Table 3 is that, as the hypothyroidism becomes more severe (i.e., a higher TSH and a lower $\mathrm{fT}_{4}$ ), the gonadotropins fall (both $\mathrm{LH}$ and FSH had an inverse correlation with TSH) and the PRL rises (an inverse correlation of PRL and $\mathrm{fT}_{4}$ was seen). Patients with hyperprolactinemia $(1,158.6 \mathrm{pmol} / \mathrm{L})$ had more profound hypothyroidism (a higher TSH and a lower $\mathrm{T}_{4}$ ). Furthermore, patients with hypoestrogenemia $\left(\mathrm{E}_{2}<73.42 \mathrm{pmol} / \mathrm{L}\right)$ had higher TSH levels, i.e., they too had more profound hypothyroidism. This suggests a potential adverse impact of the hypothyroid milieu on $\mathrm{E}_{2}$ as well.

Further elucidation would lie with the changes observed after $\mathrm{T}_{4}$ replacement. After the attainment of euthyroid status, we permitted a further 2 months to lapse before we sampled our patients again in order to ensure that changes in the HPG axis following the correction of the thyroid status would have had time to set in. We also took care to collect the blood samples once again during the early follicular phase of a natural cycle or following progesterone withdrawal.

After treatment, while there were no changes in the levels of gonadotropins, the $\mathrm{E}_{2}$ level rose significantly and PRL fell (Table 4). Furthermore, the number of hyper- 
prolactinemic patients decreased from $5 / 40$ to $1 / 40$. Hekimsoy et al. [12] also found PRL elevation in 36\% of patients with overt hypothyroidism and $22 \%$ of patients with subclinical hypothyroidism. The PRL level decreased to normal in all patients after thyroid functions were normalized with L-thyroxine treatment.

Intuitively, it would appear that correction of hypothyroidism had no effect on the function of the hypothalamo-pituitary component of the HPG axis, as the LH and FSH remained the same. However, it may be noted that while the gonadotropins did remain the same, they did so in the context of a higher level of $\mathrm{E}_{2}$. It may be argued that the feedback set point for $\mathrm{E}_{2}$, i.e., the level of $E_{2}$ that is sensed and maintained by the hypothalamo-pituitary unit rose, so that the tonic activity of the entire HPG axis had risen post-treatment. If this were not so, the rise in $\mathrm{E}_{2}$ would have resulted in the suppression of $\mathrm{LH}$ and $\mathrm{FSH}$, rather than both maintaining their baseline level. The activity of the entire axis from its origin in the hypothalamus must therefore have been stimulated because the gonadotropin levels remained the same, in spite of the heightened feedback effects from the elevated $\mathrm{E}_{2}$. Almost identical results were obtained by Saran et al. [8].

Since the level of $\mathrm{E}_{2}$ rose after correcting the hypothyroidism, while the gonadotropin levels remained the same, this could also be interpreted to mean that the bioactivity of the secreted LH and FSH increased. Low bioactivity of gonadotropins in women with hypothyroidism was previously reported by Tomasi et al. [13]. The bioactivity of the gonadotropins depends upon their posttranslation modification, mainly sialilation (i.e., the addition of sialic acid moieties to the newly translated protein). This aspect needs to be studied further.

Results from other studies also suggest that hypothyroidism is associated with reduced activity of the HPG axis in women. Distiller et al. [14] studied 7 postmenopausal hypothyroid women. Two of these 7 patients had a basal $\mathrm{LH}>2$ SD below that in healthy postmenopausal controls, while $3 / 5$ patients had an inadequate LH response to gonadotropin-releasing hormone.

Teleologically, it makes sense for the HPG axis to be suppressed during hypothyroidism, as reproductive success cannot be guaranteed during any chronic illness that reduces the state of health of a potential mother. During states of hypometabolism and ill health, the survival of the individual would naturally take priority over reproduction.

The results of the single patient that we excluded as an outlier are not contradictory to the observation that the activity of the HPG axis improves after correction of hypothyroidism. The only odd point was that, while her level of $E_{2}$ was considerably higher post-treatment, the gonadotropins rose (inexplicably) to very high levels typically seen in primary hypogonadism, even though she continued to have regular menstrual cycles. This increase in gonadotropin levels may have been because of some transient "rebound" phenomenon after hypothyroidism (the original cause of the HPG axis suppression) was corrected. The fall in PRL observed in this patient following treatment was consistent with what we observed in the other 40 patients.

Receptors for TSH and triiodothyronine $\left(\mathrm{TR}_{\alpha}\right.$ and $\mathrm{TR}_{\beta}$ ) are present on the granulosa cells of the antral follicles $[15,16]$. However, their role in follicular growth and aromatase activity in humans, independent of gonadotropins, is not known. In rats, however, $\mathrm{T}_{3}$ synergizes with FSH to promote proliferation and inhibit the apoptosis of granulosa cells [17]. As there was no gonadotropin elevation at baseline in our patients, the lower estrogen was unlikely to be predominantly a result of a direct impact of hypothyroidism on the ovarian follicles. Rather, this may have been only one contributory factor to a more general impact on the HPG axis.

\section{PRL and Its Role in HPG Axis Dysfunction in Hypothyroid Women}

At baseline, a strong inverse correlation was observed between PRL and $\mathrm{E}_{2}(r=-0.422 ; p=0.007)$. PRL level was higher and gonadotropins were lower in patients with hypoestrogenemia than in those without (Table 2). Furthermore, the reduction in serum PRL, coupled with the rise in serum $\mathrm{E}_{2}$, after correction of the hypothyroidism suggests that hyperprolactinemia may at least be in part be responsible for a lower level of functioning of the HPG axis (reflected in the lower baseline $\mathrm{E}_{2}$ ) in hypothyroid women.

The exact contribution of hypothyroidism acting directly on the HPG axis and acting indirectly through hyperprolactinemia could not be teased out in this study. This could possibly only be studied if hyperprolactinemia alone were corrected with dopamine agonists, without correcting the hypothyroidism, and then observing the changes in $\mathrm{E}_{2}$, a study which would be considered unethical. However, given that only a minority of women (5/40) were hyperprolactinemic and even the median PRL of 613 (IQR 426-821.7) pmol/L at baseline was not grossly elevated, it is unlikely that PRL alone is the cause of the lower $\mathrm{E}_{2}$ in untreated hypothyroid women. 
To conclude, hypothyroidism is associated with reversible partial suppression of the HPG axis in premenopausal women, along with mild hyperprolactinemia. Treatment of hypothyroidism improves the levels of estrogen and lowers the levels of PRL. The impact of this mild hypoestrogenemia on the libido, bone strength, and endometrium needs to be studied.

\section{Statement of Ethics}

All study participants provided a written informed consent.

\section{Disclosure Statement}

There were no conflicts of interest.

\section{References}

1 Vanderpump MP, Tunbridge WM, French JM, Appleton D, Bates D, Clark F, et al. The incidence of thyroid disorders in the community: a twenty-year follow-up of the Whickham Survey. Clin Endocrinol (Oxf). 1995 Jul; 43(1):55-68.

2 Cavaliere H, Abelin N, Medeiros-Neto G. Serum levels of total testosterone and sex hormone binding globulin in hypothyroid patients and normal subjects treated with incremental doses of L-T4 or L-T3. J Androl. 1988 May-Jun;9(3):215-9.

3 Donnelly P, White C. Testicular dysfunction in men with primary hypothyroidism; reversal of hypogonadotrophic hypogonadism with replacement thyroxine. Clin Endocrinol (Oxf). 2000 Feb;52(2):197-201.

4 Kumar A, Chaturvedi PK, Mohanty BP. Hypoandrogenaemia is associated with subclinical hypothyroidism in men. Int J Androl. 2007 Feb;30(1):14-20.

5 Velázquez EM, Bellabarba Arata G. Effects of thyroid status on pituitary gonadotropin and testicular reserve in men. Arch Androl. 1997 Jan-Feb;38(1):85-92.

6 Jaya Kumar B, Khurana ML, Ammini AC, Karmarkar MG, Ahuja MM. Reproductive endocrine functions in men with primary hypothyroidism: effect of thyroxine replacement. Horm Res. 1990;34(5-6):215-8.
7 Wortsman J, Rosner W, Dufau ML. Abnormal testicular function in men with primary hypothyroidism. Am J Med. 1987 Feb;82(2): $207-12$.

8 Saran S, Gupta BS, Philip R, Singh KS, Bende SA, Agroiya P, et al. Effect of hypothyroidism on female reproductive hormones. Indian J Endocrinol Metab. 2016 Jan-Feb;20(1):10813.

9 Krassas GE, Poppe K, Glinoer D. Thyroid function and human reproductive health. Endocr Rev. 2010 Oct;31(5):702-55.

10 Garber JR, Cobin RH, Gharib H, Hennessey JV, Klein I, Mechanick JI, et al.; American Association Of Clinical Endocrinologists And American Thyroid Association Taskforce On Hypothyroidism In Adults. Clinical practice guidelines for hypothyroidism in adults: cosponsored by the American Association of Clinical Endocrinologists and the American Thyroid Association. Thyroid. 2012 Dec; 22(12):1200-35.

11 Sawin CT, Hershman JM, Boyd AE 3rd, Longcope C, Bacharach P. The relationship of changes in serum estradiol and progesterone during the menstrual cycle to the thyrotropin and prolactin responses to thyrotropin-releasing hormone. J Clin Endocrinol Metab. 1978 Dec;47(6):1296-302.

12 Hekimsoy Z, Kafesçiler S, Güçlü F, Özmen B. The prevalence of hyperprolactinaemia in overt and subclinical hypothyroidism. Endocr J. 2010;57(12):1011-5.
13 Tomasi PA, Fanciulli G, Zini M, Demontis MA, Dettori A, Delitala G. Pulsatile gonadotrophin secretion in hypothyroid women of reproductive age. Eur J Endocrinol. 1997 Apr; 136(4):406-9.

14 Distiller LA, Sagel J, Morley JE, Oxenham E. Assessment of pituitary gonadotropin reserve using luteinizing hormone-releasing hormone (LRH) in states of altered thyroid function. J Clin Endocrinol Metab. 1975 Mar; 40(3):512-5.

15 Colicchia M, Campagnolo L, Baldini E, Ulisse S, Valensise H, Moretti C. Molecular basis of thyrotropin and thyroid hormone action during implantation and early development. Hum Reprod Update. 2014 Nov-Dec;20(6): 884-904.

16 Aghajanova L, Lindeberg M, Carlsson IB, Stavreus-Evers A, Zhang P, Scott JE, et al. Receptors for thyroid-stimulating hormone and thyroid hormones in human ovarian tissue. Reprod Biomed Online. 2009 Mar;18(3):33747.

17 Zhang C, Guo L, Zhu B, Feng Y, Yu S, An N, et al. Effects of 3, 5, 3'-triiodothyronine (t3) and follicle stimulating hormone on apoptosis and proliferation of rat ovarian granulosa cells. Chin J Physiol. 2013 Oct;56(5):298-305. 